\title{
A Compendium of Cancer Therapeutic Strategies and their Modality
}

Lakshmi Prasanna ${ }^{1 *}$, Subrahmanyam V² and Sathish Kumar $D^{3}$

${ }^{1}$ University College of Science, Osmania University, Hyderabad, India

${ }^{2}$ Department of Biochemistry, University of Hyderabad, Hyderabad, India

${ }^{3}$ Department of Biotechnology, University of Hyderabad, Hyderabad, India

\begin{abstract}
The main objective of cancer therapy is to prop up the death of cancer cells without any damage to surrounding healthy tissue. Our knowledge of molecular changes in cancer cells has enhanced the development of various therapeutic strategies to treat cancer cells. Now we are in an ideal position to utilize our knowledge of cancer cell biology in the designing of novel cancer therapies. This review is to highlight various specific and selective approaches (Chemotherapy, Radiotherapy, Surgery, Biological therapy) to understand its modality and current progress in cancer treatment.
\end{abstract}

Keywords: Targeted cancer therapies; Radio-sensitizers; Radioprotectors; Intensity-modulated radiation therapy; Gamma Knife surgery; Reactive oxygen species; Apoptosis; Biological response modifiers

Abbreviations: IMRT: Intensity-Modulated Radiation Therapy; GKS: Gamma Knife Surgery; ROS: Reactive Oxygen Species; BRMs: Biological Response Modifiers; CNTs: Carbon Nanotubes; MWCNT: Multi walled carbon nanotubes; CLL: Chronic Lymphocytic Leukemia; CSFs: Colony Stimulating Factors; OCHs: Orbital Cavernous Hemangiomas; TN: Trigeminal Neuralgia; LAK: Lymphokine-Activate Killer; CLL: Chronic Lymphocytic Leukemia.

\section{Introduction}

Cancer is a class of disease characterized by abnormal growth of cells which tend to proliferate in an uncontrolled way. There are over 100 different types of cancer, and each is classified by the type of cell that is initially affected. Cancer harms the body when damaged cells divide uncontrollably to form lumps called tumors. Tumors can be Benign or Malignant. Benign tumors are non-cancerous and can usually be removed. They do not spread to other parts of the body whereas malignant tumors are cancerous and show metastasis i.e. cancer cells break away from a malignant tumor and enter the bloodstream or lymphatic system to form secondary tumors in other parts of the body. The frequency of a particular cancer may depend on gender. While skin cancer is the most widespread type of malignancy for both men and women, the second most common type in men is prostate cancer and in women, breast cancer.

The main objective of this review article is to identify the modality (necessity or possibility or impossibility) of cancer therapies. Cancer therapies can be mainly categorized into four major groups.

- Chemotherapy

- Radiation therapy

- Surgery

- Biological therapy

Over the years chemotherapy i.e. the use of drugs has been successfully used to kill the cancer cells or stop them from multiplying [1]. The principle behind chemotherapy is its ability to halt cell division in cancer cells. Since the main reason behind the failure of cancer therapies is the emergence of genetic mechanisms of drug resistance by the cancer cells, use of new agents that may be given along with chemotherapy drugs to overcome this resistance is under study [2]. In induction chemotherapy high doses of anticancer drugs such as cisplatin [3] and methotrexate are given as preliminary treatment in order to make subsequent treatment (such as radiotherapy) more successful [4-6]. Likewise neoadjuvant chemotherapy is given prior to surgery to shrink a cancer thereby reducing the amount of healthy tissue getting damaged during the surgical procedure [7-9].

Radiotherapy is used to treat many different types of cancer. In this a beam of radiation is targeted towards the cancer cells wherein these radiations destroy the DNA inside the cancer cells with minimal damage to surrounding healthy tissue. Radiation therapy can be classified as external-beam radiation therapy $[10,11]$ if the radiation is delivered by a machine outside the body or internal radiation therapy (more commonly called Brachytherapy) $[12,13]$ if the radioactive material is placed inside the body near the cancer cell $[14,15]$. Radioactive isotopes are sealed in tiny pellets or seeds and then are delivered to target tissue using devices like catheters, needles, or some other type of carriers.

Surgery was the first modality used successfully in the treatment of cancer. Surgery is frequently used to remove the cancerous growth but the possibility of surgical cure depends on the size, location and stage of the cancer growth [16]. It helps to stop many types of cancer and also plays a part in diagnosing, staging and supporting cancer treatment. Supportive surgery is done with other types of treatment and helps other cancer treatment's work effectively [17]. The first line treatment for ovarian cancer is debulking surgery during which the tumor tissue is located and removed as much as possible [18-22]. A follow up study

*Corresponding author: Lakshmi Prasanna N, University College of Science, Osmania University, India, E-mail: prasanna_105@yahoo.in

Received December 05, 2011; Accepted December 15, 2011; Published December 17, 2011

Citation: Lakshmi Prasanna N, Subrahmanyam V, Sathish Kumar D (2011) A Compendium of Cancer Therapeutic Strategies and their Modality. J Cancer Sci Ther S17. doi:10.4172/1948-5956.S17-010

Copyright: (C) 2011 Lakshmi Prasanna N. This is an open-access article distributed under the terms of the Creative Commons Attribution License, which permits unrestricted use, distribution, and reproduction in any medium, provided the original author and source are credited. 
of patients who underwent surgical excision of cerebral anteriovenous malformations showed that the patients were in good condition with less morbidity and mortality rate $[23,24]$.

The major limitation of cancer therapy is lack of selectivity of therapeutic agents towards the target tumor cells. Current efforts are focused on developing anticancer agents that selectively destroys the tumor cells with minimal damage to the surrounding tissue. One such therapy is Biological therapy. In biological therapy body's immune system is stimulated to fight cancer or to lessen the side effects caused by other cancer treatments. It is also called as biotherapy or immunotherapy [25-28].

A brief focus on cutting edge cancer therapies are as follows:

- Targeted cancer therapies

- Intensity-modulated radiation therapy (IMRT)

- Gamma Knife surgery (GKS)

- Reactive oxygen species (ROS)

- Biological response modifiers

- Bacterial therapy: an ideal cancer therapy

- Apoptosis in cancer therapy

- Budding of nanotechnology in fight against cancer: Carbon Nanotubes

\section{Targeted Cancer Therapies}

Flooding the body with chemotherapy drugs has been one mode of treating the cancer for many decades. The debilitating side effects have finally forced the researchers to look at certain better therapies. Targeted cancer therapy is one such therapy [29]. Drugs used in this therapy are designed such that they interfere with specific molecules (targets) involved in tumor growth and progression. Targeted therapies interfere with a variety of cellular processes and inhibit the cancer growth [30]. Once a target is identified which plays a key role in cancer growth and development, a therapy must be developed. Most targeted therapies are either monoclonal antibodies or small molecule drugs.

- By blocking specific enzymes and growth factors involved in cancer cell proliferation. For example Velacade is a new anticancer drug called a proteosome inhibitor. Proteosomes are found in all cells and controls cell growth and function. By interfering with proteosomes work velacade may cause cancer cells to die. Cancer cells are more sensitive to velacade when compared to normal cells [31-34].

- By modifying the function of proteins that regulate gene expression.

- By blocking the growth of blood vessels to tumors. E.g. Sunitinib, Sorafenib [35].

- By helping the immune system to destroy cancer cells.

- Using monoclonal antibodies that specifically deliver toxic molecules to cancer cells [36,37].

- Inducing the cancer cells to undergo apoptosis.
For example, the drug Herceptin, targets the over expressing protein HER2/neu in tumor cells. Circulating liposomes linked to anti-HER2 monoclonal antibody fragments containing the drug doxorubicin that deliver it to target tumor is used to treat Breast cancer [38]. Another promising class of drugs is EGFR tyrosine kinase inhibitor for lung cancer. By inhibiting different genes in the pathway like NF-Kappa Beta which regulates cell division and death cells can be made more sensitive to the drug.

Chemicals called Radio-sensitizers that increase the sensitivity of cancer cells to radiation therapy and another group of chemicals called Radio-protectors that protect normal cells from damage caused by radiation therapy are also under study by the researchers. For example, a class of drug called MEK inhibitors is currently in clinical trials for different types of cancer. Chemoembolization which is a combination of chemotherapy and embolization uses drugs that are directly injected into the blood vessel feeding the cancer tissue and are mostly limited to hepatocellular carcinoma [39].

\section{Intensity-modulated Radiation Therapy (IMRT)}

IMRT allows higher radiation doses to be focused to regions within the tumor while minimizing the dose to surrounding normal critical structures [40]. IMRT can reduce the risk of some side effects, such as damage to the salivary glands (which can cause dry mouth) when the head and neck are treated with radiation therapy [41]. The side effects of IMRT are the same as those of conventional radiation therapy but tend to occur less frequently and with less intensity in the short and long term. Before the advent of this method the maximum radiation dosage was restricted by the impact it would have on nearby tissues. For instance, when conventional radiation therapy is utilized to treat lung or breast cancer, some overlap of radiation may occur to the arteries of the heart. For a few patients, this may necessitate a bypass operation in the future. With IMRT for the lung or breast tumor, the radiation overlap to the heart arteries is shown to be minimal or non-existent, possibly eliminating the need for further invasive care and/or heart problems [42].

Radiation therapy may be used alone or in combination with surgery, chemotherapy, or both. Sometimes radiation therapy may also be given with palliative intent. Cetuximab, a monoclonal antibody against epidermal growth factor receptor in combination with radiotherapy is a standard option in the treatment of head and neck carcinoma [43,44]. Radioembolization is a combination of radiation therapy and embolization. It is a minimal invasive technique hence produces fewer side effects. In this technique tiny resin beads are placed inside blood vessels which feed a tumor as a result blocking the supply of blood to the tumor cells $[45,46]$. Helical tomotherapy machine is a hybrid between a CT imaging scanner and an external-beam radiation therapy machine. It is a type of image-guided IMRT [47,48]. In recent times it has been introduced for the cure of hepatocellular carcinoma. Helical tomotherapy obtains an image from the computed tomography module, which allows targeted regions to be visualized former to, during, and immediately following each treatment and delivers intensity-modulated radiation therapy $[49,50]$.

\section{Gamma Knife Surgery (GKS)}

Gamma Knife surgery is one of the most advanced means to treat tumors mainly brain tumors. It is a unique non-invasive neurosurgical technique in which no surgical incision is performed to expose the 
target. Using Stereotactic radiosurgery technique gamma knife uses gamma rays to precisely target and destroy the tumor tissue in the skull [51,52]. Gamma rays are so finely focused that the surrounding healthy tissue are not damaged.

The Gamma Knife contains up to 201 cobalt-60 sources of approximately 30 curies each, placed in a circular array in a heavily shielded unit. Based on preoperative radiological examinations, such as CT scans, MR scans and angiography, the unit provides highly accurate irradiation of deep-seated targets. The high energy light beams damage the DNA of tumor cells. If enough damage is done to the DNA, the tumor cell will die spontaneously or it will die the next time it tries to divide into two cells. Radiation therapy destroys the tumors by splitting the oxygen molecules it finds in and around tumors into harmful oxygen radicals that destroy tumor cells.

1. Gamma knife surgery is proved beneficial in treating conditions which were considered to be non-treatable. For example:

2. Benign tumors including: acoustic neuromas, meningiomas, and pituitary adenomas craniopharyngiomas [53,54].

3. Tumors located at the base of the skull in the pineal region.

4. The clinical outcome shows that in $90 \%$ of the patients a decrease in tumor size was observed in case of orbital cavernous hemangiomas (OCHs) [55].

5. Gamma Knife surgery offers an satisfactory rate of tumor control for posterior fossa meningiomas and accomplishes this with a low frequency of neurological deficits.

6. Gamma Knife surgery (GKS) is regarded as the first-line treatment in patients with trigeminal neuralgia (TN)

7. Gamma Knife surgery (GKS) is a recognized treatment modality for brain metastases.

Advantages of Gamma Knife surgery:

1. It is a neurosurgical tool designed exclusively for the treatment of brain disorders.

2. The tumor being treated receives a high dose of radiation with minimum risk to nearby healthy tissues.

3. Its cost is often $25 \%$ to $30 \%$ less than traditional neurosurgery.

4. The absence of an incision eliminates the risk of hemorrhage and infection.

5. The procedure offers hope to patients who were formerly considered untreatable or at very high risk during open skull surgery.

\section{Reactive Oxygen Species (ROS)}

Reactive oxygen species (ROS) plays an important role in various normal biological functions as well as abnormal pathological processes [56-58]. ROS influences proliferation, apoptosis and senescence which are implicated in the development of cancer. Damage to the DNA by ROS is the major cause of cancer. If the mutation induced by ROS is related to genes such as oncogenes or tumor suppressor genes, initiation or development of cancer may result. In spite of its impact in cancer development, ROS can be exploited for the development of novel therapeutic strategies to preferentially kill cancer cells [59]. ROS controls the expression of various tumor suppressor genes such as p53, Rb, PTEN [60,61]. Likewise gamma radiations and various other chemotherapeutic agents used to treat cancer mediate their effect through ROS [62].

\section{Biological Response Modifiers}

Biological response modifiers assist in the following ways:

- Make the cancer cells more recognized by the immune system.

- Boost the killing power of immune system cells.

- Change the way cancer cells grow, so that they act more like healthy cells.

- Stop the process that changes a normal cell into a cancerous cell.

- Enhances the body's ability to repair or replace normal cells damaged or destroyed by other forms of cancer treatment, such as chemotherapy or radiation.

- Prevents cancer cells from spreading to other parts of the body.

Current approaches include the use of preferentially replicating bacteria as an oncolytic agent for the treatment of cancer. This is based on an observation that some anaerobic bacteria (facultative or obligate) are capable of multiplying selectively in tumors and inhibiting there growth. Substances called biological response modifiers (BRMs) are naturally produced in the body in response to infection and diseases. These BRMs can be produced in the laboratory by using modern laboratory techniques and can be used for the treatment of cancer. Examples of biological therapy include: interferons, interleukins, colony stimulating factors, monoclonal antibodies, vaccines, gene therapy, and nonspecific immunomodulating agents [63-65]. Biological therapies also cause side effects like nausea, vomiting, diarrhea, weakness, fever, etc.

\section{Interferon}

Interferons are one of the biological response modifiers that naturally occur in the body. It is a hormone like protein produced by white blood cells. These can be made in the laboratory and used to shrink or stop the growth of cancer cells. Some interferon's stimulate the growth of lymphocytes which then destroys the cancer cells $[66,67]$. The side effects with this include fever, chills, muscle and joint aches, and fatigue. Interferon alpha has been approved by FDA for the treatment of certain types of cancer like AIDS-related Kaposi's sarcoma, chronic myeloid leukemia, hairy cell leukemia and melanoma. Beta interferons are used primarily in the treatment for multiple sclerosis. Gamma interferons are used in the treatment of chronic granulomatous disease $[68,69]$.

\section{Interleukin}

Interleukins are glycoproteins that occur naturally in the body and can also be made in the laboratory. It plays an important role in cancer treatment by stimulating T-lymphocyte activation and proliferation, promotion of B-lymphocytes and multilineage bone marrow stem cell precursor growth and differentiation. They interfere with the way cancer cells grow and multiply. The side effects with this include fatigue, diarrhea, and low levels of blood cells and loss of appetite. IL-2 
(aldesleukin) has already gained FDA approval for the treatment of renal cell carcinoma and metastatic melanoma. IL-2 enhances various T-cell functions and natural killer or NK cell function. IL-2 also activates lymphokine-activate killer (LAK) cells, which are a form of killer $\mathrm{T}$ cell formed when lymphocytes are incubated with IL-2. LAK cells destroy tumor cells and improve the recovery of immune function in certain immunodeficiency states [70].

\section{Monoclonal antibodies}

Monoclonal antibodies are made in the laboratory. These are designed such that they attack only the cancer cells.

There are two types of monoclonal antibodies that are used in cancer treatment:

- Naked monoclonal antibodies (without any drug or radioactive material attached to them)

- Conjugated or tagged or labeled monoclonal antibodies (with chemotherapy drug or radioactive material attached to them)

The first monoclonal antibodies approved by the FDA to treat any cancer were Rituximab (naked MoAb) and Ibritumomab tiuxetan which is also called Zevalin (conjugated MoAb). Zevalin locks onto a protein called CD20 on the surface of B- cells, a main type of white blood cells. CD20 is present on both normal B-cells and abnormal B-cells in many types of non-Hodgkin lymphoma. As soon as Zevalin locks onto the $\mathrm{B}$-cells it releases radiations that damage the cancer cells. Some normal cells are also damaged but these can be replaced by the body. Likewise Alemtuzumab (Campath) is another group of antibody that locks onto protein called CD52 found on the surface of lymphocytes [71,72]. It is mainly used to treat chronic lymphocytic leukemia (CLL).The ongoing clinical trials with monoclonal antibodies are focused towards a wide range of cancers like breast cancer, non-hodgkin's lymphoma, chronic lymphocytic leukemia, colorectal cancer and sarcomas.

\section{Colony stimulating factors (CSFs)}

Colony stimulating factors are proteins that stimulate the stem cells within the bone marrow to produce more blood cells and promote their ability to function. They do not have any direct influence on cancer but through their role in stimulating blood cells they help to boost the immune system. CSFs are given along with chemotherapy enabling the patient to receive higher doses of chemotherapy. Some examples are as follows:

a. G-CSF (filgrastim) and GM-CSF (sargramostim) increases the number of white blood cells, thereby reducing the side effects in patients receiving chemotherapy. G-CSF and GM-CSF can also stimulate the production of stem cells in preparation for stem cell or bone marrow transplants [73].

b. Erythropoietin (epoetin) increases the number of red blood cells and decreases the need for red blood cell transfusions in patients receiving chemotherapy.

c. Interleukin-11 (oprelvekin) helps the body to build platelets and can lessen the need for platelet transfusions in patients receiving chemotherapy.

\section{Bacterial Therapy: An Ideal Cancer Therapy}

Cancer requires surgery, chemotherapy or radiotherapy all of which wreak havoc on the patient during and often long after treatment.
Several decades after Coley's work a variety of natural and genetically modified non-pathogenic bacterial species are being explored as potential antitumor agents, either to provide direct tumoricidal effects or to deliver tumoricidal molecules. These genetically modified nonpathogenic bacterial species are capable of multiplying selectively in tumors. These bacteria and their spores also serve as ideal vectors for delivering therapeutic proteins to tumors because of their selectivity for tumor tissues.

The majority of solid tumors contain regions of low oxygen or dead tissue. This environment encourages the growth of certain bacteria such as the Clostridium family, making them a perfect agent to deliver anti-cancer treatments. A new Clostridium strain, C. novyi-NT made non-pathogenic by genetic modification, is under clinical trials [74]. New genetic engineering tools, such as the group II intron has shown promise for genetic manipulation of bacteria and forecast the dawn of a new era for a tumor-targeted bacterial vector system for gene therapy of solid tumors. It remains to be seen whether anaerobic bacterial treatment of cancer will prove to be as effective as is hoped due to the limitations of oxygen concentrations. In the end the development of combination therapies may result in novel approaches.

Bacteria can also be used to increase the efficacy of chemotherapy. Bacterial strains to express enzymes for selective prodrug activation and non-invasive imaging in tumors have been developed. For example, beta-glucuronidase and the luxCDABE gene cluster were expressed in the DH5alpha strain of Escherichia coli to generate DH5alpha-lux/ betaG. These bacteria preferentially replicated within CL1-5 human lung tumors, emitted light for imaging and hydrolyzed the glucuronide prodrug 9ACG to the topoisomerase I inhibitor 9-aminocamptothecin (9AC). Combined systemic administration of DH5alpha-lux/betaG followed by 9 ACG prodrug treatment significantly $(\mathrm{P}<0.005)$ delayed the growth of CL1-5 tumors. This occurs in two steps: In the first step, the bacteria are administered (at safe levels) that target the tumor where they proliferate and express the therapeutic enzyme. In the second step, once the expression of the enzyme is optimal, a non-toxic prodrug is administered which is converted to the cytotoxic drug at the tumor by the expressed enzyme. This results in tumor cytotoxicity rather than systemic toxicity, leading to tumor cell death and sparing normal tissue [75].

\section{Apoptosis in Cancer Therapy}

Apoptosis which is also called as programmed cell death has attracted the attention of so many researchers in recent years because of two major advances. Firstly, a large number of apoptosis regulating genes have been identified in Caenorhabditis elegans. Mammalian homologs of these genes shows the evidence that cell death is an active process under genetic control. Secondly, studies on signal transduction pathways of apoptosis have led to the identification of certain death signaling molecules such as caspases [76]. Recently it has been observed that dysregulation of apoptotic programs may lead to cancer and other diseases.

The current focus is to study the apoptotic regulation and its role in cancer and to come up with new therapeutic concepts. Novel molecules that prop up apoptosis by targeting both the intrinsic and extrinsic apoptotic pathways may lead to the development of effective cancer therapies $[77,78]$. One such molecule is $\mathrm{p} 53$ protein which causes apoptosis by activating the pro-apoptotic genes in tumor cells. 


\section{Budding of Nanotechnology in Fight against Cancer: Carbon Nanotubes}

Over the last few years many different biological nanomaterials have been developed among which CNTs are widely used in cancer therapy. CNTs are tubular materials of nanometer-sized diameter and axial symmetry, giving them exceptional properties that can be exploited in the identification and treatment of cancer. Nanomaterials such as carbon nanotubes (CNTs), quantum dots, and dendrimers have distinctive properties that can be exploited for diagnostic purposes and drug delivery in cancer [79]. In addition, CNTs have the potential to deliver drugs directly to targeted cells and tissues. The contour of the CNT would permit these materials to enter the cell via different methods, like passive diffusion across the lipid bilayer, or endocytosis. The CNT then attaches to the surface of the cell and is consequently engulfed by the cell membrane [80]. The hollow monolithic structure of CNTs and their capacity to bind preferred functional groups make CNTs potential drug carriers. Different functional groups can be attached to make them more water-soluble and serum-stable, with little toxicity at the cellular level. For e.g. MWCNT (Multi walled carbon nanotubes) has been found to motivate the proliferation of lymphocytes. Its administration in mice strongly enhanced the production of IFN- $\gamma$-secreting and TNFsecreting CD8+ T cells. Most statistics point out that TNF stimulates innate immunity both in vitro and in animal models and stimulates the production of other cytokines (e.g. IL-1, IL-6, and IL-8) and cytotoxic agents (e.g. nitric oxide and reactive oxygen species) by macrophages, which can further mediate tumor suppression [81].

\section{Conclusion}

Besides traditional chemotherapy, surgical excision and radiation therapy, there are many other effective treatments for cancer. A number of first-line therapies such as Targeted cancer therapy, biological response modifiers, GKS and IGRT, bacterial therapy have come up and will give a better competition to the present cancer therapies due to fewer side effects. A blend of recombinant DNA technology along with immunotherapy applied to the anaerobic bacteria will serve as the foundation for the multimodality curative strategies for cancer. Recent advancement in understanding the molecular changes that underlie cancer development offer the panorama of specifically targeting malfunctioning molecules and pathways to achieve more efficient and rational cancer therapy. Advance investigation and developments in these studies will put in a new dimension to cancer treatment.

\section{References}

1. Shafik AN, Khodeir MM, Fadel MS (2011) Animal study of Anthracyclineinduced Cardiotoxicity and Nephrotoxicity and Evaluation of Protective Agents. J Cancer Sci Ther 3: 096-103.

2. Kurioka D, Takagi A, Yoneda M, Hirokawa Y, Shiraishi T, et al. (2011) Multicellular Spheroid Culture Models: Applications in prostate Cancer Research and Therapeutics. J Cancer Sci Ther 3: 060-065.

3. Hamed RH, Elzahaf E (2011) Low Dose Weekly Paclitaxel Versus Low Dose Weekly Cisplatin with Concomitant Radiation in Locally Advanced Head and Neck Cancers. J Cancer Sci Ther 3: 168-172.

4. Akasbi Y, Arifi S, Ousadden A, Tizniti S, Amarti A, et al. (2011) Complete Pathologic Response in Advanced Primary Gastric Signet-Ring Cell Carcinoma: A Case Report. J Cancer Sci Ther 3: 076-078.

5. Oualla K, Arifi S, Tizniti S, El Mesbahi O (2011) Intracranial Hypertension Syndrome Revealing Cerebral Thrombophlebitis in a Patient treated for Breast Cancer by Tamoxifen after Chemotherapy. J Cancer Sci Ther 3: 195-196.
6. H Bismuth, R Adam, F Lévi, C Farabos, F Waechter, et. al (1996) Resection of nonresectable liver metastases from colorectal cancer after neoadjuvant chemotherapy. Ann Surg 224: 509-522.

7. Khorate MM, Goel S, Singh MP, Ahmed J (2010) Osteosarcoma of Mandible: A Case Report and Review of Literature. J Cancer Sci Ther 2: 122-125.

8. Yokoe H, Kasamatsu A, Ogawara K, Ishigami T, Sato Y, et al. (2010) Neoadjuvant Chemotherapy with S-1 for Patients with Oral Squamous Cell Carcinoma. J Cancer Sci Ther 2: 132-135.

9. Song WZ, Wang Z, Li LW, Chen JH, Wang J (2010) Evaluation of Early Response to Neoadjuvant Chemotherapy in Breast Cancer Patients by 18F-FDG and 99mTc-HL91 Imaging. J Nucl Med Radiat Ther 1: 102.

10. Tebeu PM, Verkooijen HM, Popowski Y, Bouchardy C, Ludicke F, et al. (2011) Impact of External Radiotherapy on Survival after Stage I Endometrial Cancer: Results from a Population-Based Study. J Cancer Sci Ther 3: 041-046.

11. Hsu A, Frank SJ, Ballo MT, Garden AS, Morrison WH, et. al (2008) Postoperative adjuvant external-beam radiation therapy for cancers of the eyelid and conjunctiva. Ophthal Plast Reconstr Surg 24: 444-449.

12. Biswal BM, Ahmad NM, Hanafia ZA, Zakaria A, Othman NH, et al. (2011) Pilot Study on Continuous Hyperfractionated Accelerated Radiotherapy (CHART) and High Dose Rate Brachytherapy in Locally Advanced Cervical Cancer. J Cancer Sci Ther 3: 125-129.

13. Bonnet-Duquennoy M, Papon J, Mishellany F, Denoyer D, Labarre P, et al (2009) Promising Pre-clinical Validation of Targeted Radionuclide Therapy Using a [131I] Labelled lodoquinoxaline Derivative for an Effective Melanoma Treatment. J Cancer Sci Ther 1: 001-007.

14. Nishio M, Sakurai T, Kagami Y, Narimatsu N. (1987) Brachytherapy of cancer Gan To Kagaku Ryoho 14: 1519-1530.

15. Wiffen PJ. (2011) Low-dose rate brachytherapy for men with localized prostate cancer. J Pain Palliat Care Pharmacother 25: 375.

16. Singh V, Sinha RJ, Sankhwar SN, Mehrotra B, Ahmed N, et al. (2010) Squamous Cell Carcinoma of the Kidney - Rarity Redefi ned: Case Series with Review of Literature. J Cancer Sci Ther 2: 082-085.

17. Tripathi P, Nahar P, Padmavathi BN, Ahmed J (2010) Adenoid Cysic Carcinoma of the Palate: A Case Report with Review of Literature. J Cancer Sci Ther 2: 160-162.

18. Cafà EV, Angioli R, Scollo P (2010) Ovarian Carcinoid Tumor with Nodal Metastases: Case Report. J Cancer Sci Ther 2: 120-121.

19. van der Burg ME, van Lent M, Buyse M, Kobierska A, Colombo N, et al. (1995) The effect of debulking surgery after induction chemotherapy on the prognosis in advanced epithelial ovarian cancer. N Engl J Med 332: 629-634.

20. Piver MS, Lele SB, Marchetti DL, Baker TR, Tsukada Y, et al. (1988) The impact of aggressive debulking surgery and cisplatin-based chemotherapy on progression-free survival in stage III and IV ovaria carcinoma. J Clin Oncol 6: 983-989.

21. Le T, Krepart GV, Lotocki RJ, Heywood MS. (1997) Does debulking surgery improve survival in biologically aggressive ovarian carcinoma? Gynecol Oncol 67: 208-214

22. Lawton FG, Redman CW, Luesley DM, Chan KK, Blackledge G. (1989) Neoadjuvant (cytoreductive) chemotherapy combined with intervention debulking surgery in advanced, unresected epithelial ovarian cancer. Obstet Gynecol 73: 61-65.

23. Wang JF, Repertinger-Fisher S, Mittal SK, Deng C (2011) A Large Esophageal Granular Cell Tumor with Review of Literature. J Cancer Sci Ther 3: 213-215.

24. Heros RC, Korosue K, Diebold PM. (1990) Surgical excision of cerebral arteriovenous malformations: late results. Neurosurgery 26: 570-577

25. Lechleider R, Pastan I (2011) Advances in the Development of AntiCD22Immunotoxins Containing Pseudomonas Exotoxin for Treatment of HematologicMalignancies. J Cancer Sci Ther 3: 050-052.

26. Sinnathamby G, Zerfass J, Hafner J, Block P, Nickens Z, et al. (2011) EDDR1 is a Potential Immunotherapeutic Antigen in Ovarian, Breast, and Prostate Cancer. J Clin Cell Immunol 2: 106. 
Citation: Lakshmi Prasanna N, Subrahmanyam V, Sathish Kumar D (2011) A Compendium of Cancer Therapeutic Strategies and their Modality. J Cancer Sci Ther S17. doi:10.4172/1948-5956.S17-010

Page 6 of 7

27. Dronca RS, Markovic SN, Holtan SG, Porrata LF (2011) Neuroendocrineimmune Crosstalk and Implications for Cancer Therapy. J Cell Sci Ther 2: 102e

28. Lu X, Shi J, Yao Q, He J, Zhou Y, et al. (2011) Adoptive Immunotherapy Against Malignant Glioma Using Survivin-specific CTLs Expanded by W6/32 Antibody-mediated Artificial Antigen-presenting Cells. J Cell Sci Ther 2: 110.

29. Nagy MA (2011) HIF-1 is the Commander of Gateways to Cancer. J Cancer Sci Ther 3: 035-040.

30. Demeure MJ, Bussey KJ, Kirschner LS (2011) Targeted Therapies for Adrenocortical Carcinoma: IGF and Beyond. Horm Cancer 2: 385-392.

31. Essadi I, Sbitti Y, Ichou M, Errihani H (2011) The Role of Chemotherapy in the Treatment of Kaposi's Sarcoma. J Cancer Sci Ther 3: 145.

32. Oliveira JP, Magliarelli HF, Pereira FV, Gianotti A, Soares-Costa A, et al. (2011) Sugarcane Cystatin CaneCPI-4 inhibits Melanoma Growth by Angiogenesis Disruption. J Cancer Sci Ther 3: 161-167.

33. Yaari-Stark S, Nevo-Caspi Y, Jacob-Hirsch J, Rechavi G, Nagler A, et al. (2011) Combining the Ras Inhibitor Salirasib and Proteasome Inhibitors: A Potential Treatment for Multiple Myeloma. J Cancer Sci Ther 3: 187-194.

34. Singh RK, Sudhakar A, Lokeshwar BL (2010) Role of Chemokines and Chemokine Receptors in Prostate Cancer Development and Progression. J Cancer Sci Ther 2: 089-094.

35. Matsuda Y, Fukumoto M (2011) Sorafenib: complexities of Raf-dependent and Raf-independent signaling are now unveiled. Med Mol Morphol 44: 183-189.

36. El Mesbahi O, El M'rabet FZ (2011) Reversible Hepatic Cytolysis Secondary to Sunitinib in Metastatic Renal Carcinoma. J Cancer Sci Ther 3: 047-049.

37. Sharkey RM, Goldenberg DM (2006) Targeted therapy of cancer: new prospects for antibodies and immunoconjugates. CA Cancer J Clin 56: 226-243.

38. Bareggi Renato NV, Paola N (2010) New Targeted Therapies Against Breast Cancer. J Carcinogene Mutagene 1: 110.

39. Hao M, Lin H, Chen Q, Yu W, Zhou D, et al. (2011) Efficacy of Transcatheter Arterial Infusion Alone or Combined with Transcatheter Arteria Chemoembolization on Advanced Hepatocellular Carcinoma. J Cancer Sci Ther 3: 130-133.

40. Aljarrah K, Pawlicki T, Tyagi N, Jiang SB (2010) Evaluation of IMRT QA Poin Measurement Rocesses Using a Commercial Heterogeneous Phantom. J Cancer Sci Ther 2: 063-069.

41. Aljarrah K, Pawlicki T, Niemierko A, Mell LK, Jiang SB (2010) A Clinical Study of MLC-Based IMRT Lung Dose Calculation Accuracy on Plan Evaluation Parameters. J Cancer Sci Ther 2: 074-081.

42. Shao ZY, Tang ZS, Yan C, Jiang YT, Ma R, et al. (2011) Effects of Intensitymodulated Radiotherapy on Human Oral Microflora.J Radiat Res (Tokyo) 52: 834-839.

43. Kumar R, Sharma SD, Amols HI, Mayya YS, Kushwaha HS (2010) A Survey on the Quality Assurance Procedures Used in Intensity Modulated Radiation Therapy (IMRT) at Indian Hospitals. J Cancer Sci Ther 2: 166-170.

44. Mesía R, Vilajosana E, Lozano A, Esteller L, Silvia V (2009) Management of Cutaneous Toxicity and Radiation Dermatitis in Patients with Squamous Cancer of the Head and Neck Undergoing Concurrent Treatment with Cetuximab and Radiotherapy. J Cancer Sci Ther 1: 028-033.

45. Gayed IW, Wahba H, Wan D, Joseph U, Murthy R (2010) Effect of Y-90 SIRSpheres Therapy for Multiple Liver Metastases in a Variety of Tumors. J Cancer Sci Ther 2: 043-046.

46. Mihaylov IB, Lerma FA, Moros EG (2010) Relation Between Tumor Size and Range of Motion in IMRT Treatment Planning for Thoracic Lesions. J Cancer Sci Ther 2: 095-099.

47. He W, Vazquez LA, Dzintars E, Papanikolaou N, Shi C (2010) Assessing the Dosimetric Consequence of Inter-fractional Setup Shifts on Helical TomoTherapy Plans with Independent Dose Calculation. J Cancer Sci Ther 2: $136-144$.

48. Papanikolaou N, He W, Vazquez LA, Gutierrez A, Stathakis S, et al. (2010)
MU-Tomo: Independent Dose Validation Software for Helical TomoTherapy. J Cancer Sci Ther 2: 145-152.

49. Franco $P$, Catuzzo P, Cante D, La Porta MR, Sciacero $P$, et al. (2011) TomoDirect: an efficient means to deliver radiation at static angles with tomotherapy. Tumori 97: 498-502.

50. Kim JS, You CR, Jang JW, Bae SH, Choi JY, et al. (2011) Application of helical tomotherapy for two cases of advanced hepatocellular carcinoma. Korean $J$ Intern Med 26: 201-206.

51. Dea N, Borduas M, Kenny B, Fortin D, Mathieu D (2010) Safety and efficacy of Gamma Knife surgery for brain metastases in eloquent locations. J Neurosurg 113: 79-83.

52. Pan HC, Sheehan J, Huang CF, Sheu ML, Yang DY, et al. (2010) Quality-oflife outcomes after Gamma Knife surgery for trigeminal neuralgia. J Neurosurg 113: 191-198

53. Mathieu D, Deacon C, Pinard CA, Kenny B, Duval J (2010) Gamma Knife surgery for hypothalamic hamartomas causing refractory epilepsy: preliminary results from a prospective observational study. J Neurosurg.113: 215-221.

54. Starke RM, Nguyen JH, Rainey J, Williams BJ, Sherman JH, et al. (2011) Gamma Knife surgery of meningiomas located in the posterior fossa: factors predictive of outcome and remission. J Neurosurg. 114: 1399-1409.

55. Liu X, Xu D, Zhang Y, Liu D, Song G (2010) Gamma Knife surgery in patients harboring orbital cavernous hemangiomas that were diagnosed on the basis of imaging findings. J Neurosurg 113: 39-43.

56. Chhetri P, Lee C, Rakesh L (2011) Molecular Modeling Studies of Interaction Between Plasmid DNA (pBR322) and Dendritic Antioxidants. J Cancer Sci Ther 3: $220-227$.

57. Pelicano H, Carney D, Huang P (2004) ROS stress in cancer cells and therapeutic implications. Drug Resist Updat 7: 97-110.

58. Gulam Waris, Haseeb Ahsan (2006) Reactive oxygen species: role in the development of cancer and various chronic conditions. J Carcinog 5: 14

59. Ramachandran S, Sarkar S, Mazumadar A, Mandal M (2011) Azurin Synthesis from Pseudomonas Aeruginosa MTCC 2453, Properties, Induction of Reactive Oxygen Species, and p53 Stimulated Apoptosis in Breast Carcinoma Cells. J Cancer Sci Ther 3: 104-111.

60. Shimul S, Rajiv G (2010) MTA1 Aids the AKT Pathway by Inhibiting Expression of a Key Regulator, PTEN. J Cancer Sci Ther 2: 114-119.

61. Jasmine G, Yogeshwer S (2008) Prognostic Factors of Male Breast Cancer: Proteomic Approaches for Early Detection and Treatment. J Proteomics Bioinform 1: 112-127.

62. Singh RK, Sudhakar A, Lokeshwar BL (2011) From Normal Cells to Malignancy: Distinct Role of Pro-inflammatory Factors and Cellular Redox Mechanisms. J Cancer Sci Ther 3: 070-075.

63. Tagawa M (2000) Cytokine therapy for cancer. Curr Pharm Des 6: 681-699.

64. Skopec R (2011) Mechanism Linking Aggression Stress through Inflammation to Cancer. J Cancer Sci Ther 3: 134-139.

65. Debta P, Debta FM, Chaudhary M, Wadhwan V (2011) Evaluation of Prognostic Significance of Immunological Cells (Tissue Eosinophil and Mast Cell) Infiltration in Oral Squamous Cell Carcinoma. J Cancer Sci Ther 3: 201-204.

66. Vashistha S, Ajitkumar P (2011) Exposure to Interferon g Decreases Levels and Activity of Key Cell Cycle Proteins Resulting in Severe Growth Arrest of the Human Non-Transformed Cell Line, WISH. J Cancer Sci Ther 3: 013-019.

67. Müller CR, Namløs HM, Bjerner J, Østensen IHG, Sæter G, et al. (2010) Characterization of Treatment Response to Recombinant Interferon-2b in Osteosarcoma Xenografts. J Cancer Sci Ther 1: 016-025.

68. Tsimafeyeu I, Demidov L, Kharkevich G, Petenko N, Volkova M, et al. (2010) Granulocyte-Macrophage Colony-Stimulating Factor, Interferon Alpha and Interleukin-2 as Adjuvant Treatment for High-Risk Renal Cell Carcinoma. J Cancer Sci Ther 2: 157-159.

69. Lindberg E, Andersson B, Eggertsen R, Nyström E, Magnusson Y (2010) 
Citation: Lakshmi Prasanna N, Subrahmanyam V, Sathish Kumar D (2011) A Compendium of Cancer Therapeutic Strategies and their Modality. J Cancer Sci Ther S17. doi:10.4172/1948-5956.S17-010

A Polymorphism at Position +874 in The IFN-y Gene is Associated with Susceptibility for Dilated Cardiomyopathy. J Clin Cell Immunol 1: 101.

70. Elmslie RE, Dow SW, Ogilvie GK (1991) Interleukins: biological properties and therapeutic potential. J Vet Intern Med. 5: 283-293.

71. Mayes S, Brown N, Illidge TM (2011) New antibody drug treatments for Iymphoma. Expert Opin Biol Ther 11: 623-640.

72. Gopal AK, Press OW, Wilbur SM, Maloney DG, Pagel JM (2008) Rituximab blocks binding of radiolabeled anti-CD20 antibodies (Ab) but not radiolabeled anti-CD45 Ab. Blood 112: 830-835.

73. Matsuda E, Okabe K, Tao H, Yamamoto H, Hirazawa K, et al. (2011) [Clinical assessment of granulocyte colony-stimulating factor producing lung cancer]. Kyobu Geka 64: 445-449

74. Wei MQ, Mengesha A, Good D, Anné J (2008) Bacterial targeted tumour therapy-dawn of a new era. Cancer Lett 259: 016-027.

75. Cheng CM, Lu YL, Chuang KH, Hung WC, Shiea J, et al. (2008) Tumortargeting prodrug-activating bacteria for cancer therapy. Cancer Gene Ther 15: 393-401.
76. Karmakar S, Roy Choudhury S, Banik NL, Ray SK (2010) Activation of Multiple Molecular Mechanisms for Increasing Apoptosis in Human Glioblastoma T98G Xenograft. J Cancer Sci Ther 2: 107-113.

77. Yuan Y, Zhang YS, Qu XJ (2011) The Molecular Alterations Regarding Apoptosis in Hepatocellular Carcinoma Cells at a Glance. J Carcinogene Mutagene 2: 118.

78. Ferreira AK, Meneguelo R, Neto SC, Chierice GO, Maria DA (2011) Synthetic Phosphoethanolamine Induces Apoptosis Through Caspase-3 Pathway by Decreasing Expression of Bax/Bad Protein and Changes Cell Cycle in Melanoma. J Cancer Sci Ther 3: 053-059.

79. Madani SY, Naderi N, Dissanayake O, Tan A, Seifalian AM (2011) A new era of cancer treatment: carbon nanotubes as drug delivery tools. Int J Nanomedicine 6: 2963-2979.

80. Elhissi AM, Ahmed W, Hassan IU, Dhanak VR, D'Emanuele A (2012) Carbon nanotubes in cancer therapy and drug delivery. J Drug Deliv 2012.

81. lancu C, Mocan L (2011) Advances in cancer therapy through the use of carbon nanotube-mediated targeted hyperthermia. Int J Nanomedicine 6: 1675-1684. 